\title{
Influence of physical and chemical properties on the low-frequency complex conductivity of peat
}

\author{
M. Ponziani ${ }^{*}$, E.C. Slob ${ }^{1}$, H. Vanhala ${ }^{2}$ and D.J.M. Ngan-Tillard ${ }^{1}$ \\ ${ }^{1}$ Department of Geotechnology, Delft University of Technology, Stevinweg 12628 CN Delft, the Netherlands \\ ${ }^{2}$ Geological Survey of Finland, Betonimiehenkuja 4, 02150 Espoo, Finland
}

Received March 2011, revision accepted July 2011

\begin{abstract}
Organic layers are heterogeneous in space and their composition changes over time. This poses challenges to ecohydrologists, subsurface hydrologists and ground engineers in characterizing subsurface peat structures and predicting their behaviour over time. Peat deposits can be characterized by performing electrical surveys, provided that the complex conductivity of peat is understood and connected to its physical and chemical properties. Low-frequency $(0.1-1000 \mathrm{~Hz})$ induced polarization measurements were carried out to investigate the correlation between the chemical and physical properties of several peat samples and their electrical properties. A Cole-Cole model was fit to the peat spectra to obtain the model parameters and study their relationship with the sample properties. All the samples were characterized by analysing their degree of humification, water content, organic content, cation exchange capacity, $\mathrm{pH}$ and conductivity of the pore-fluid. Two significant correlations between physical, chemical and electrical properties are found. The peat bulk conductivity is directly correlated with the pore fluid conductivity, whereas the degree of humification of peat shows an inverse correlation with the phase angle. This study presents results that have implications for peatland characterization with frequency dependent or single frequency analysis of induced polarization measurements.
\end{abstract}

\section{INTRODUCTION}

The low-frequency polarization of inorganic sediments originates in the polarization of the electrical double layer formed at the solid-fluid interface and it is a function of the surface chemical properties, the pore solution chemistry and the microgeometrical properties of the sample (Lesmes and Frye 2001). In organic media the surface activity is determined by functional groups that carry a negative charge. The total amount of cations absorbed by the negatively charged surface of peat is called cation exchange capacity $(C E C)$. Very diverse values of peat $C E C$ are found in literature, because $C E C$ varies with species composition (Rippy and Nelson 2007). Thorpe (1973) reported a range of values from humus $(65 \mathrm{cmol} / \mathrm{kg})$ to sphagnum moss peat $(122 \mathrm{cmol} / \mathrm{kg}$ ), which has a much higher $C E C$ than other plants (Moore and Bellamy 1974), whereas a much lower value (10.6 cmol/kg) was found for fen peat (Gogo and Pearce 2009).

A peatland is a dynamic system due to the decomposition of organic matter by microflora, bacteria and fungi. During the humification process, the composition of peat changes, with the production of biogenic gas and dissolved humic acids. Humic acids absorb and exchange many cations and are therefore a source of peat CEC (Szalay 1964). A relationship between CEC and humification is expected because as peat decomposes, there

*m.ponziani@tudelft.nl is an increase of charged organic acid functional groups. Reported values for moss peats show that $C E C$ increases from $100-124 \mathrm{cmol} / \mathrm{kg}$ when the humification increases from not decomposed (H1) to moderate decomposed (H5) peat (Puustjarvi and Robertson 1975). During the decomposition of the organic matter, peat also undergoes a structural change, going from a fibrous structure to a granular isotropic state. This loss of structure reduces the amount of water that can be retained by the peat (Landva and Pheeney 1980). Moreover, changes in porosity have an influence on the conductivity of peat, as pore-throat diameters and pore geometry of water-saturated geo-materials contribute significantly to both in-phase and out-of-phase conduction at low-frequencies (Scott and Barker 2003). Cosenza et al. (2007) showed that changes in both water content and texture affect the spectral induced polarization response during the shrinkage of clay; textural changes are determined by loss of water in the micropores and thus the low-frequency polarization is not controlled by macropores (Ghorbani et al. 2009). Independently of the soil texture, soil compaction has an influence on both the conductive properties (Seladji et al. 2010) and the polarization response (Koch et al. 2010) of porous media; as a result of consolidation tests on peat (Ponziani et al. 2011), the compression during a stage of consolidation primarily affects the peat conductivity response and has a minor effect on the polarization response. For the physical and chemical changes occurring dur- 
ing the degradation process, also a change in induced polarization response is expected for different degrees of humification of the organic matter.

Recently, induced polarization measurements have been used in peat to study the depth and thickness of layers (Slater and Reeve 2002; El-Qady et al. 2005), to detect archaeological remains (Weller et al. 2006) and to estimate the surface area to pore volume (Mansoor and Slater 2007). Moreover, electrical conductivity measurements provide information about peatlands morphology and stratigraphy, which is strongly correlated with the vegetation patterning (Comas et al. 2004). Field observations of the peat conductivity present very diverse values, from a few to hundreds mS/m (e.g., Siegel 1988; Theimer et al. 1994), typically increasing with depth, when the underlying layer is a mineral soil that releases inorganic solutes (Slater and Reeve 2002). The conductivity response of peat depends on the conductive properties of both the fluid saturating the peat and the surface of the solid grains in contact with the fluid. In contrast with Archie's law (Archie 1942), the bulk conductivity depends nonlinearly on the pore fluid and is modelled by including a power law accounting for the phenomenon of pore space dilation, which occurs when the pore fluid salinity increases (Comas and Slater 2004). However, fully saturated conditions do not always apply, due to the production of biogenic gases by the organic matter. The biogenic gases produced affect the electrical measurements by reducing the peat conductivity response; this is due to the displacement of conductive fluid from the peat pores and to the increase of porosity as a result of deformation of the organic matter (Slater et al. 2007). As the complex conductivity of peat is primarily affected by the pore-fluid conductivity and the peat structure (Kettridge et al. 2008), induced polarization measurements may indicate properties such as the degree of humification of peat, providing a useful tool for ground investigation and soil classification. This work aims to improve the electrical characterization of peat, determining which peat property is controlling the complex conductivity response of peat from a different origin and composition.

Laboratory measurements of the low-frequency complex conductivity were conducted over the frequency range $0.1-1000 \mathrm{~Hz}$ on Finnish and Dutch peat samples. The results were analysed and related to the physicochemical properties of the samples, to establish the controlling parameters of the electrical response. A Cole-Cole model was fitted to the peat samples spectra and model parameters were analysed and discussed.

\section{EXPERIMENTAL SET UP}

\section{Laboratory methods}

For each sample a peat block was collected, saturated with groundwater and sealed in a plastic bag. Once in the lab, the peat samples were stored in a dark climate room at $10^{\circ} \mathrm{C}$. Each peat block was cut and subsampled to obtain a specimen with the same volume as the experimental cell. The specimen was carefully placed in the experimental cell, trying to preserve the original compaction and texture of the peat. One limitation of this technique is that it requires subsampling; however, due to the high compressibility of peat and the presence of fibres, perfectly undisturbed samples of soft soils cannot be extracted (La Rochelle et al. 1981) and disturbance can only be reduced to minimize the effects on the soil matrix and degree of compression. We assume that the disturbance during sampling and preparation of the specimen is minor compared to the textural difference among the samples, which covers a wide range of degrees of humification, from very fibrous low-humified peat to an amorphous highly decomposed peat.

The conductivity amplitude and phase response of the peat samples were acquired with a four-electrode configuration using a two-channel dynamic signal analyser (HP 35665A), which operates over the frequency range $16 \mathrm{mHz}$ to $51 \mathrm{kHz}$. The experimental cell used for the electrical measurements is a glass tube with an internal diameter of $34.5 \mathrm{~mm}$. The current electrodes were goldplated disks placed at the extremities of the tube. The voltage was measured between platinum electrodes of length $30 \mathrm{~mm}$ and diameter $1.8 \mathrm{~mm}$, with an electrode separation of $220 \mathrm{~mm}$. The electrodes were connected to the analyser through a pre-amplifier, which is characterized by high input impedance to reduce the polarization of potential electrodes and low output impedance to reduce capacitive coupling effects. A detailed description and schematic diagram of the system including the effects of sampling, sample preparation and potential electrodes used is given in Vanhala and Soininen (1995). The phase accuracy of the system is frequency-dependent and depends on the sample properties. For the frequency range $0.1 \mathrm{~Hz}$ to $1 \mathrm{kHz}$ and the resistivity of the peat samples tested, the phase accuracy is better than $1 \mathrm{mrad}$ (Vanhala and Soininen 1995).

The real $\left(\sigma^{\prime}\right)$ and imaginary $\left(\sigma^{\prime}\right)$ components of the complex conductivity $\left(\sigma^{*}\right)$ can be computed from the measured phase angle $(\phi)$ and amplitude $(|Z|)$ of the impedance according to the geometrical factor, which is the ratio between the electrode distance $(d)$ and the electrode area $(A)$ :

$\sigma^{*}=\sigma^{\prime}+i \sigma^{\prime \prime}=\frac{\cos (-\varphi)}{|Z|} \frac{d}{A}+i \frac{\sin (-\varphi)}{|Z|} \frac{d}{A}$.

Considering the high water content and saturation of the peat samples (with an average of 92.6\%), temperature corrections for both the bulk conductivity and the pore fluid conductivity were based on the functional dependence of water conductivity (Keller and Frischknecht 1966) on temperature $T$ (in ${ }^{\circ} \mathrm{C}$ ), given by

$\sigma_{(T)}^{\prime}=\sigma_{\left(20^{\circ} C\right)}^{\prime}(1+\alpha(T-20))$,

where $\alpha=0.025^{\circ} \mathrm{C}^{-1}$ (Ward 1990). As tested for some of the peat samples, the low-frequency phase angle response did not significantly change in the range of temperature of the room $\left(20.0^{\circ} \mathrm{C}\right.$ $\pm 1.5^{\circ} \mathrm{C}$ ). Therefore, $\sigma^{\prime \prime}$ at $20^{\circ} \mathrm{C}$ can be derived from $\sigma^{\prime}$ at $20^{\circ} \mathrm{C}$ through the relationship 
$\sigma_{\left(20^{\circ} \mathrm{C}\right)}^{\prime \prime}=\sigma_{\left(20^{\circ} \mathrm{C}\right)}^{\prime} \tan (-\varphi)$.

For these tests, peat samples from IJkdijk (the Netherlands) and from different regions of Finland were used. Representative subsamples were selected for analysis of degree of humification $(H)$, water content $(W C)$, organic content $(O C)$, cation exchange capacity $(C E C), \mathrm{pH}$ and conductivity of the pore-fluid $\left(\sigma_{w}\right)$. Degree of humification, which represents the level of decomposition of the organic matter in the peat, was determined according to the von Post classification (von Post 1922). Water content was determined based on the weight loss of the bulk peat after drying $24 \mathrm{~h}$ at $105^{\circ} \mathrm{C}$ (den Haan and Kruse 2007). We define water content as the ratio between the mass of water contained in the sample and the total mass of the sample. Organic content was determined based on the weight loss on ignition at $500^{\circ} \mathrm{C}$ (den Haan and Kruse 2007) and corrected with a formula proposed by Skempton and Petley (1970). The cation exchange capacity was measured on $2 \mathrm{~g}$ of air-dried peat according to a protocol described by Thorpe (1973) and recently used for CEC measurements on moss peats (Rippy and Nelson 2007). A peat sample was shaken with $0.5 \mathrm{~N} \mathrm{HCl}$ to displace the adsorbed cations and saturate exchange sites with $\mathrm{H}^{+}$. The suspension was filtered, washed and soaked in a $0.5 \mathrm{~N}$ solution of barium acetate to replace $\mathrm{H}^{+}$with $\mathrm{Ba}^{2+}$. The suspension was filtered and washed with $300 \mathrm{ml}$ of $\mathrm{H}_{2} \mathrm{O}$. Washings were collected and titrated with $0.1 \mathrm{~N}$ solution of sodium hydroxide, using phenolphthalein as an indicator. The conductivity and $\mathrm{pH}$ of the fluid extracted from the samples by compression with the compression cell were measured using a conductivity meter LF 340 and a pH meter WTW 330i, respectively.

\section{Calibration of the cell}

The reliability of the electrical response of the set-up has been studied testing distilled and saline water. The calibration aims to determine the best setting for the pre-amplifier and the frequency range in which the complex conductivity spectra are stable and repeatable with high precision. The measured spectra were compared with the theoretical $\sigma^{*}$ values according to

$\sigma^{*}=i \omega \varepsilon^{*}$,

where precise values of $\varepsilon^{*}$ as a function of temperature and salinity of the electrolyte solution were determined from the equations derived by Stogryn (1971).

Figure 1(a) shows theoretical values of $\sigma_{w}$ for distilled (DW) and saline water $(\mathrm{SW})$ compared with experimental data $(\sigma)$, and Fig. 1(b) the phase error $\left(\varphi_{e r r}\right)$ obtained as the difference between the measured and the theoretical phase angle, with error bars that define the accuracy of the measurements (1 mrad). The four-electrode configuration of the system is effective to determine the real conductivity below the $\mathrm{kHz}$ range. At low frequencies, the error in the phase angle response is low both for distilled and saline water $\left(\sigma_{S W}=88 \mathrm{mS} / \mathrm{m}\right)$. Above $100 \mathrm{~Hz}$, the phase error increases due to the capacitive coupling effect, which depends on the sample resistance but also on the pre-amplifier properties and on the length of the cables. In addition to the sample resistance, the phase error depends on the contact resistance between the current and potential electrodes (Vanhala and Soininen 1995). As previously determined on the same system, the phase shift due to capacitive coupling is lower than $1 \mathrm{mrad}$ for the tested conductivities and for frequencies lower than $100 \mathrm{~Hz}$ (Vanhala and Soininen 1995).

\section{PEAT PROPERTIES}

\section{Sample properties}

The selected peats present very diverse origins and properties. One sample was collected in the field test of IJkdijk, in the Netherlands, a)

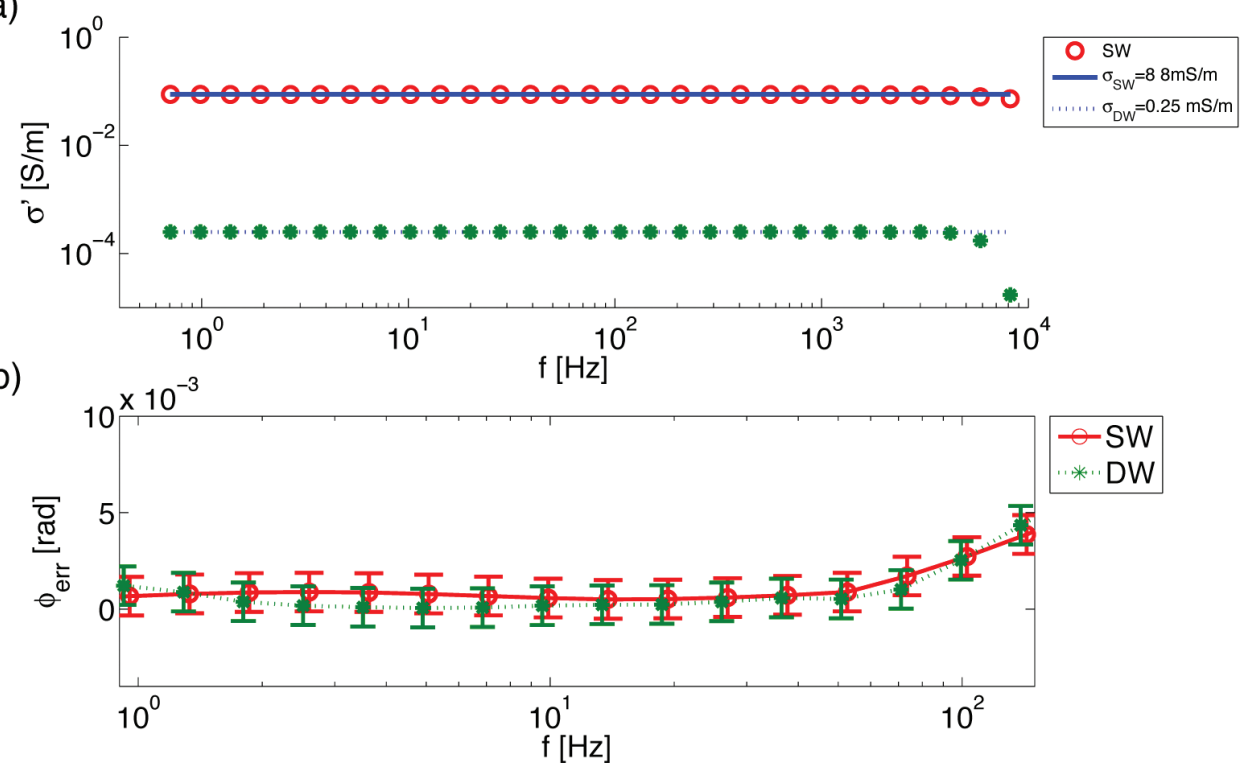

FIGURE 1

Calibration curves obtained from IP measurements on distilled (DW) and saline water (SW) samples. Theoretical curves of $\sigma_{w}$ are compared with experimental data (a); the phase error $\left(\varphi_{e r r}\right)$ is obtained as a difference between the measured and the expected phase angle (b); error bars (1 mrad) indicate the accuracy of the measurements. 
IP investigation of peat

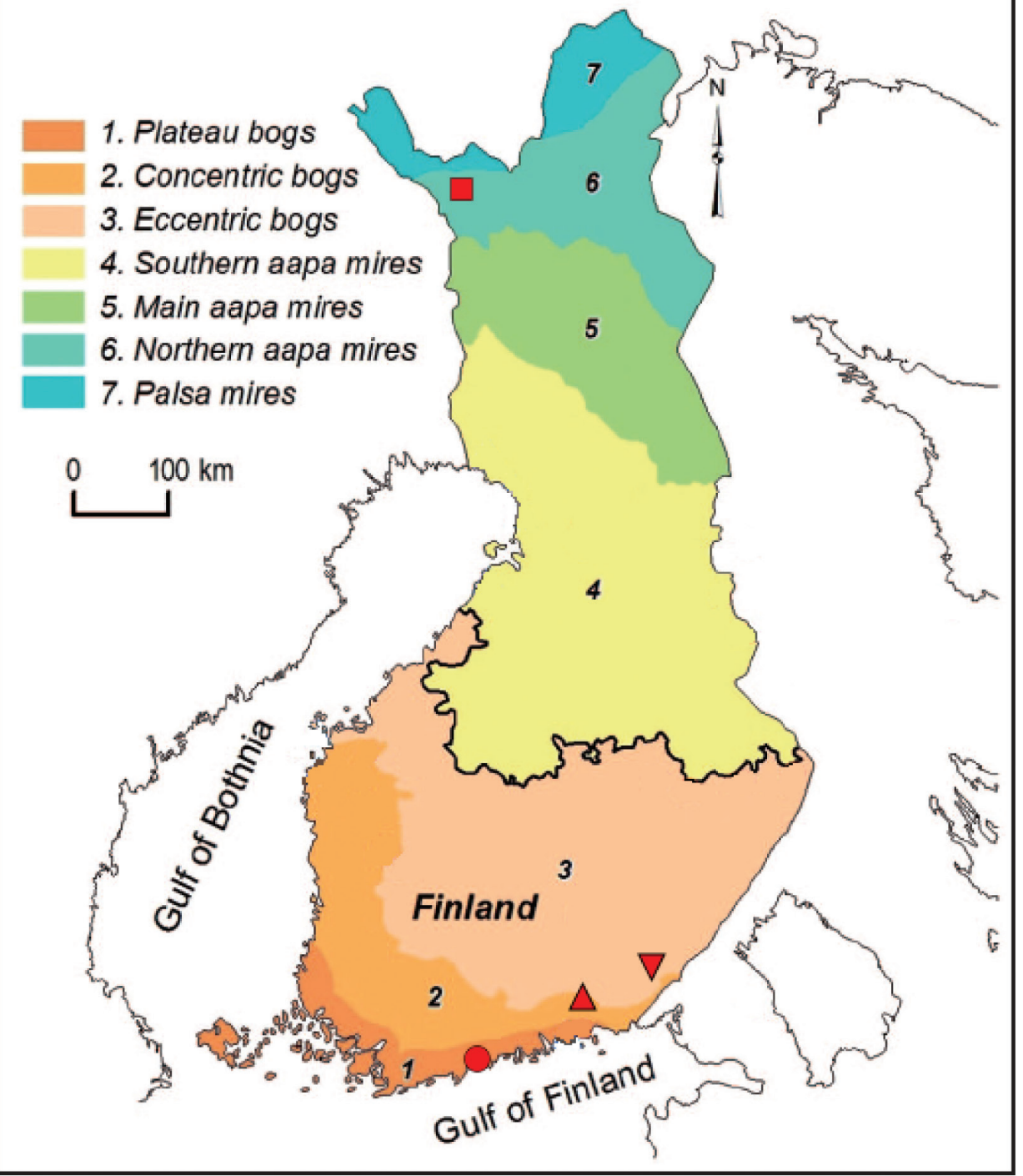

FIGURE 2

Location of the peat samples in relation to the mire complex type regions (from 1-7) of Finland (Ruuhijärvi and Hosiaisluoma 1989). Samples S1-S5 (•) were collected in the bog Mankkaan Turvesuo (Espoo), samples S6 and S7 ( $\mathbf{\Delta})$ came from Haukkasuo (Kouvola), S8 ( $)$ from Kourulansuo (Lappeenranta) and S9-S11 (ם) from Luovuoma (Enontekiö). while the other eleven samples were obtained from different mires and bogs of Finland from locations shown in Fig. 2. Mires are wetlands dominated by living peat-forming plants, while bogs are mires characterized by a vegetation of sphagnum, low trees and shrubs (Hobbs 1986; Rydin and Jeglum 2006). In Finland electrical and electromagnetic (EM) techniques have been used for the mapping of peatlands since the early 1970s. Nowadays, low altitude high-resolution airborne EM data (Airo 2005) cover the whole Finnish territory. As the electrical conductivity of peat typically differs from that of the underlying bedrock or clay, the airborne EM data have been used for regional scale mapping of peat layers thickness (Puranen et al. 1999; Säävuori and Mäkilä 2004). Detailed electrical conductivity models and sections of bogs, based mostly on electrical conductivity probe measurements
(Puranen et al. 1997), have been used for analysis of the development and structure of bogs (Puranen et al. 1999; Mäkilä 2004).

In Table 1, the classification of the peat samples for several properties is reported. Peat samples can be a mixture of two or more plant types. Their botanical composition is described by symbols for each plant type, in which the first symbol represents the principal component. For these samples, plant types were Sphagnum (S), Carex (C) and Lignidi (L). The degree of humification ranged from not-decomposed peat with intact plant structure $(H=1)$ to very strongly decomposed peat with the structure of the plants almost unrecognizable $(H=8)$. A description of the classification of peat based on its degree of decomposition is reported by Hobbs (1986). All samples had high organic content, over $90 \%$, except for the Dutch peat, for which the mineral frac- 
TABLE 1

Physical and chemical properties of the peat samples

\begin{tabular}{|c|c|c|c|c|c|c|c|c|}
\hline Sample & Origin & Type & $H$ & $W(\%)$ & $O C(\%)$ & $\begin{array}{l}C E C \\
(\mathrm{cmol} / \mathrm{kg})\end{array}$ & $p H$ & $\begin{array}{l}\boldsymbol{\sigma}_{w} \\
(\mathbf{m S} / \mathbf{m})\end{array}$ \\
\hline S1 & Espoo & $\mathrm{SC}$ & 3 & 96 & 92.7 & 97.2 & 5.1 & 38.8 \\
\hline $\mathrm{S} 2$ & Espoo & S & 2 & 92.3 & 91.9 & 61.7 & 5.2 & 26.5 \\
\hline $\mathrm{S} 3$ & Espoo & $\mathrm{CS}$ & 2 & 96.6 & 82.7 & 31.7 & 5.0 & 30.6 \\
\hline S4 & Espoo & $\mathrm{CS}$ & 2 & 96.6 & 82.7 & 31.7 & 4.6 & 11.3 \\
\hline S5 & Espoo & $\mathrm{CS}$ & 2 & 96.6 & 82.7 & 31.7 & 4.1 & 57.9 \\
\hline S6 & Kouvola & S & 7 & 92.4 & 99.1 & 77.8 & 3.6 & 41.6 \\
\hline S7 & Kouvola & $\mathrm{S}$ & 3 & 96.2 & 98.7 & 80.0 & 3.8 & 20.6 \\
\hline S8 & Lappeenranta & $\mathrm{LC}$ & 7 & 86.0 & 97.0 & 62.2 & 3.6 & 29.9 \\
\hline S9 & Enontekiö & $\mathrm{SC}$ & 3 & 86.3 & 90.1 & 60.0 & 4.7 & 24.5 \\
\hline S10 & Enontekiö & $\mathrm{S}$ & 1 & 89.0 & 97.0 & 60.0 & N/A & N/A \\
\hline $\mathrm{S} 11$ & Enontekiö & $\mathrm{SC}$ & 2 & 95.1 & 95.6 & 60.0 & 7.4 & 121.8 \\
\hline $\mathrm{S} 12$ & IJkdijk (NED) & $\mathrm{LC}$ & 8 & 90.6 & 43.3 & 48.3 & 6.8 & 119.0 \\
\hline
\end{tabular}

tion was higher than the organic fraction. The $C E C$ ranged from $31.7-97.2 \mathrm{cmol} / \mathrm{kg}$, with higher values for the sphagnum dominant plant type and lower for carex peat. Most of the peat samples were acidic, with a $p H$ ranging from 3.6-5.2, except for the last two samples, with a $p H$ around neutrality.

\section{Model of charges and conductivity of peat}

The electrochemical interaction established between charged solid particles and the electrolytic solution in contact with them is determined by the spatial distribution of ions around the charged surfaces, also called electrical double layer. A physical model to describe the electrical double layer is to divide it into two layers, one of fixed charges bound to the solid surface (Stern layer) and the other of diffuse charges within the solution in contact with the surface (Gouy-Chapman layer). The diffuse layer consists of a relatively loose ion cloud where ions can freely migrate in any direction; ionic concentration is exponentially reduced with the distance from the charged surface. The electrical potential at the plane between the fixed and mobile part of the electrical double layer is identified as the zeta potential ( $\zeta$ ). The magnitude and sign of $\xi$ depends on the interfacial chemistry of both the liquid and solid phase (Hunter 1981). The zeta potential of peat decreases when the $p H$ or the concentration of cation increases (Asadi et al. 2011). Moreover, the level of decomposition of peat affects $\zeta$, as peat with a higher degree of humification shows a higher $\zeta$ (Asadi et al. 2011). A change in the $p H$ of the pore fluid affects the surface charges of the peat, mainly due to the dissociation of $\mathrm{H}^{+}$from the functional groups. For example, carboxylic acid $(\mathrm{COOH})$ groups dissociate a proton $\left(\mathrm{H}^{+}\right)$in acidic conditions (below $\mathrm{pH}=$ 6) leaving a negative charge on the carboxyl groups ( $\left.\mathrm{COO}^{-}\right)$. The $\mathrm{pH}$ at which the peat surface has a net neutral charge is the point of zero charge $\left(\mathrm{pH}_{Z P C}\right)$; for sphagnum peat this point was identi- fied at a value of $p H_{Z P C}=3.1$ (Sepulveda-Cuevas et al. 2008).

The presence of the electrical double layer in soils with charged particles like peat has an influence on both the real and imaginary conductivity responses. At low frequency, the complex conductivity of peat is typically modelled adding a complex surface conductivity $\left(\sigma_{\text {surf }}^{\prime}+i \sigma_{\text {surf }}^{\prime \prime}\right)$ in parallel with the electrolytic conductivity $\left(\sigma_{e l}\right)$ through the bulk pore-fluid:

$\sigma^{*}=\sigma^{\prime}+i \sigma^{\prime \prime}=\sigma_{e l}+\sigma_{\text {surf }}^{\prime}+i \sigma_{\text {surf }}^{\prime \prime}$,

where the real conductivity shows a non-linear dependence on the pore fluid conductivity ( $A, b$ and $C$ are fitting parameters), as observed by Comas and Slater (2004):

$\sigma^{\prime}=A \sigma_{w}^{b}+C \sigma_{\text {surf }}^{\prime \prime}\left(\sigma_{w}\right)$,

The surface conductivity represents both the conductive and capacitive properties of the electrical double layer. In order to improve the electrical models for organic soils, the influence of physical and chemical properties on the complex conductivity and thus on the electrical double layer, has to be investigated. The lowfrequency dispersion of $\sigma^{*}$ is primarily controlled by diffusive polarization mechanisms (e.g., Chelidze and Gueguen 1999). Diffusive polarization occurs when ions migrate through the bulk pore solution due to the electric field applied and accumulate at physico-chemical discontinuities, giving a local increase of charges. The low-frequency polarization of porous media is explained by Marshall and Madden (1959) with membrane polarization mechanisms. Several theoretical models have been developed to obtain information about the microgeometry of porous materials (de Lima and Sharma 1992; Lesmes and Morgan 2001; Titov et al. 2002; Leroy et al. 2008). However, these theoretical models have been 
developed for porous media with structure and texture very different from peat and contain a large number of parameters that are difficult to constrain in many applications (Kruschwitz et al. 2010). Leroy and Revil (2009) presented a mechanistic model for $\sigma^{*}$ of saturated clay-rich materials. Jougnot et al. (2010) extended this model to unsaturated clay-rocks. These models are based on the polarization of the Stern layer, which is discontinuous, whereas the polarization of the diffuse layer, which forms a continuous phase through the porous material, is not considered.

The frequency dependent electrical response of peat can be fitted with an empirical derived model such as the Cole-Cole model (Cole and Cole 1941; Pelton et al. 1978), which has recently been used to describe the electrical response of marsh soils by Mansoor and Slater (2007). The frequency dependent behaviour of the complex conductivity is described by the relationship

$\sigma^{*}(\omega)=\sigma_{0}\left[1+m\left(\frac{(i \omega \tau)^{c}}{1+(i \omega \tau)^{c}(1-m)}\right)\right]$,

where $\sigma_{0}$ is the DC conductivity, $m$ is the chargeability, $\tau$ is the mean relaxation time and $c$ a shape exponent. A change in $\tau$ corresponds to a shift in the peak of the phase, whereas $c$ is related to the distribution of grain size and thus it determines the phase distribution, because the phase is strongly related to the polarization of the Stern layer (Jougnot et al. 2010). The relaxation time is related to the geometrical characteristics of the material (e.g., grain or pore-throat size) that determine the diffusive relaxation processes responsible for the low-frequency electrical polarization. For spectral induced polarization measurements on organic sediments, Koch et al. (2010) observed a clear correlation between the relaxation time of the ColeCole model and the hydraulic conductivity, which is determined by changes in the degree of compaction of the sample. Ghorbani et al.
(2009) showed that a change in water content during desaturation of clay-rocks does not affect the low-frequency $\tau$, whereas the highfrequency $\tau$ increases with drying. After analysing several data sets of different porous media, Kruschwitz et al. (2010) concluded that for samples with large pore throats $\tau$ increases with the pore-throat size, whereas for samples with small pore throats the diffusion length scale does not appear to be controlled by modal pore-throat size. The time constant is thus also influenced by other physical and chemical properties that affect the low-frequency diffusive mechanisms in the electrical double layer. Therefore, as the complex conductivity response of soils is controlled by coupled physicochemical polarization mechanisms, it is difficult to relate the spectral induced polarization signal to a single structural factor of a studied sample (Koch et al. 2010).

\section{RESULTS}

The complex conductivity measured in the glass tube showed that the peat samples produce a phase peak in the range $1-100 \mathrm{~Hz}$, as observed previously on organic (Mansoor and Slater 2007) and inorganic materials (Lesmes and Morgan 2001; Scott and Barker 2003). Each peat spectrum was fitted with a Cole-Cole model (Cole and Cole 1941; Pelton et al. 1978) using a trust-regionreflective algorithm, which solves non-linear least-squares problems. As expected from the calibration with water, the capacitive coupling above $100 \mathrm{~Hz}$ appears to affect the electrical response, with a relevant increase of the imaginary conductivity. For this reason, the model was fit to the spectra in the range of frequency $10^{-1}-10^{2} \mathrm{~Hz}$.

Figure 3 shows the frequency-dependent complex conductivity of two peat samples of different dominant plant types, Carex (S5) and Sphagnum (S10) and the fit of equation (7) to both data sets (solid lines). The electrical response shows a clear variabil-

\section{IP investigation of peat}

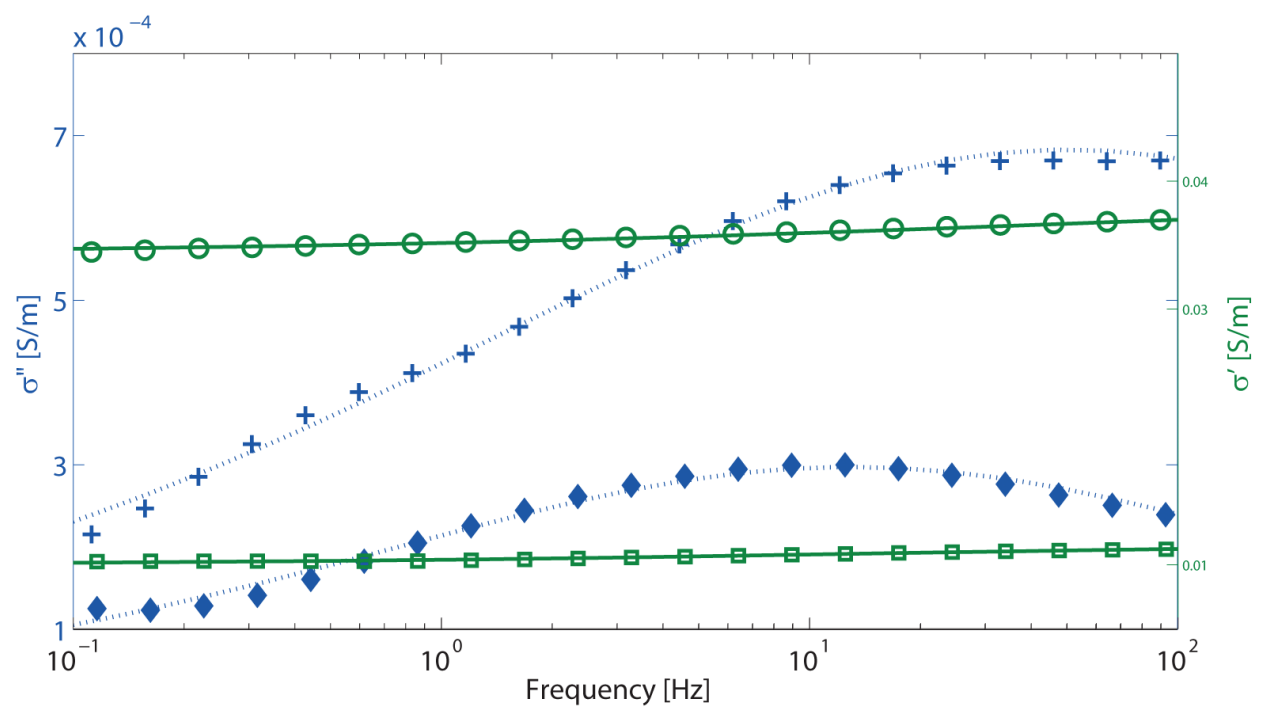

\section{FIGURE 3}

Peat spectra showing real (o) and imaginary $(+)$ conductivities of carex peat (S5) and real (ㅁ) and imaginary ( $)$ conductivities of sphagnum peat (S10) fit to a ColeCole model: continuous lines correspond to fitting lines for the real conductivity, whereas dashed lines represent fitting lines for the imaginary conductivity. 
TABLE 2

Cole-Cole model parameters and errors obtained from fitting of the peat spectra

\begin{tabular}{llllll}
\hline Sample & $\sigma_{D C}(\mathbf{S} / \mathbf{m})$ & $m$ & $t(\mathbf{s})$ & $c$ & rms $(\boldsymbol{\%})$ \\
\hline S1 & 0,0185 & 0,1304 & 0,34195 & 0,01465 & 0,07 \\
S2 & 0,0226 & 0,1574 & 0,3765 & 0,1174 & 0,31 \\
S3 & 0,0188 & 0,2154 & 0,23395 & 0,01765 & 0,15 \\
S4 & 0,01475 & 0,1626 & 0,3724 & 0,16145 & 1,10 \\
S5 & 0,0343 & 0,1221 & 0,3551 & 0,0046 & 0,35 \\
S6 & 0,0418 & 0,1384 & 0,2144 & $1,38 \mathrm{E}-06$ & 0,10 \\
S7 & 0,0162 & 0,1331 & 0,3184 & 0,0106 & 0,41 \\
S8 & 0,0447 & 0,1022 & 0,368 & 0,0022 & 0,69 \\
S9 & 0,0174 & 0,0900 & 0,3784 & 0,024 & 0,23 \\
S10 & 0,00995 & 0,1428 & 0,4367 & 0,01795 & 0,40 \\
S11 & 0,0987 & 0,0946 & 0,3512 & 0,3512 & 0,10 \\
S12 & 0,1191 & 0,0182 & 0,6632 & 0,0012 & 0,98 \\
\hline
\end{tabular}

\section{IP investigation of peat}

a)

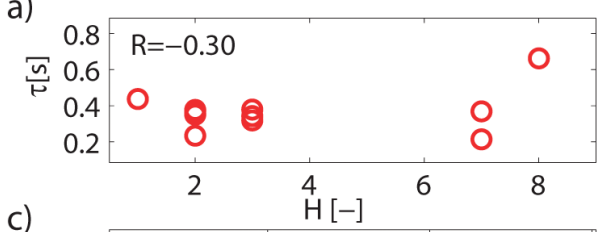

c)
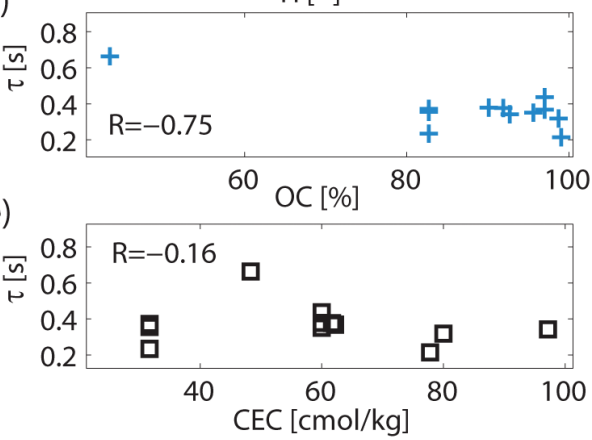

b)

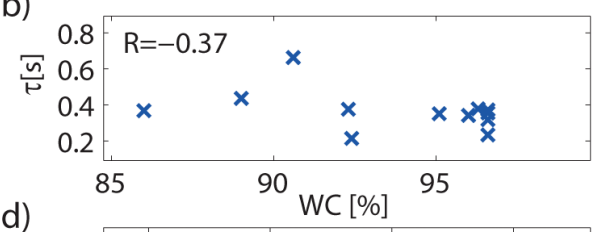

d)
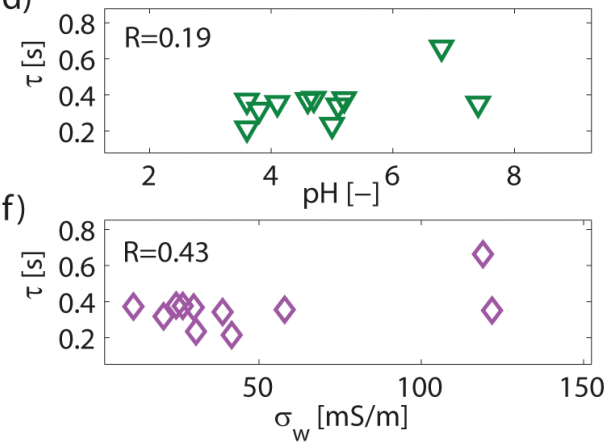

FIGURE 4

Relationships and coefficients of correlation $(R)$ between the ColeCole model parameter $\tau$ (mean relaxation time) of the Cole-Cole model and the peat sample properties. ity among the different peat samples; however, the Cole-Cole model sufficiently fits all the spectra with a maximum global root-mean-square (rms) error of $1.10 \%$ for sample S4. A complete report of model parameters and errors obtained from the fitting of all peat samples is given in Table 2. The Cole-Cole parameters obtained from the frequency analysis of the peat spectra showed no significant relationship with any of the peat samples properties reported in Table 1. The Cole-Cole parameter that contains information about the frequency behaviour of the complex conductivity is the mean relaxation time $\tau$, whose relationship with the peat sample properties is displayed in Fig. 4. It appears that none of the properties considered in this study has a direct correlation with $\tau$. The parameter that can be used as a global estimation of the interfacial polarization magnitude is the normalized chargeability $m_{n}$ (Lesmes and Frye 2001), which is the ratio between $m$ and the electrical resistivity. Mansoor and Slater (2007) showed that $m_{n}$ is proportional to the specific surface area in marsh soils, with a higher correlation for clay samples than peat. As expected, in the presented data set a linear correlation exists between $m_{n}$ and $\sigma^{\prime \prime}$ measured at $1 \mathrm{~Hz}(R=0.79)$ but no evidence of another relationship between $m_{n}$ and the sample properties was found. This result is in accordance with Fig. 5, as also none of the samples' properties can be related to $\sigma^{\prime \prime}$. 
The relationships between the electrical response of peat, in terms of conductivity and polarization and the physicochemical properties of the samples were studied to determine which properties control the induced polarization measurements of peat. Figures 5 and 6 show correlations of different peat samples properties with $\sigma^{\prime}$ and $\sigma^{\prime \prime}$, which represent the conduction and the polarization response of the material respectively. Measurements are taken at a single frequency $(1 \mathrm{~Hz})$ and corrected to a temperature of $20^{\circ} \mathrm{C}$. For the tests carried out on the 12 samples of different composition, the conductivity of the pore fluid was found to be the property with the highest coefficient of correlation with $\sigma^{\prime}$ (Fig. 6f) and thus the property that primarily affects the conductivity response. In agreement with the conclusions of Comas and Slater (2004) on organic soils, the relationship between $\sigma^{\prime}$ and $\sigma_{w}$ is non-linear $\left(\sigma^{\prime} \propto \sigma_{w}{ }^{1.6}\right)$; the experimental data also fit equation (6), where $\sigma^{\prime \prime}$ is included in the real surface conductivity but for our results the fitting parameters $A, b$ and $C$ are an average of the 12 samples and they do not identify a specific peat. With regard to the measured $\sigma^{\prime \prime}$, no clear correlation was found, as none of the sample properties had a coefficient of correlation higher than 0.80 , which we took as the threshold for significance ( $\mathrm{p}$-value $<0.002$ ). Instead, the degree of humification of the sample showed a negative inverse correlation ( $R=-0.86)$ with the phase angle of the complex conductivity (Fig. 7a), which represents the field parameter to measure the polarization; all the other properties showed low correlation with the phase response (Fig. 7b-f). This means that the phase response of the peat increases with decreasing decomposition, even for peat samples of different plant types. Therefore, among the properties

\section{IP investigation of peat}

a)

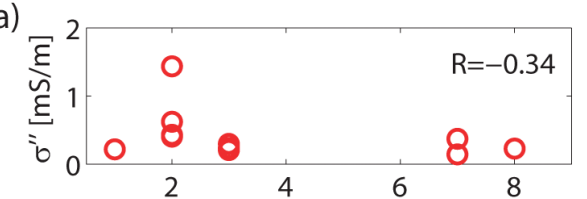

c)

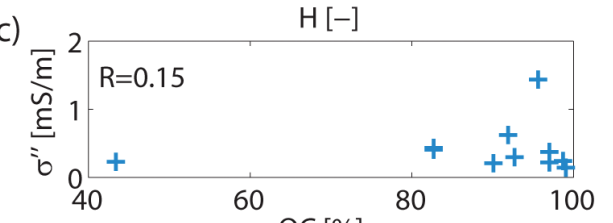

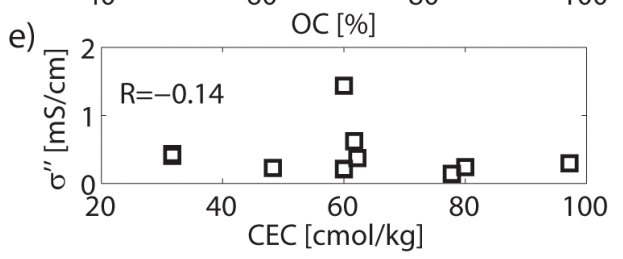

b)

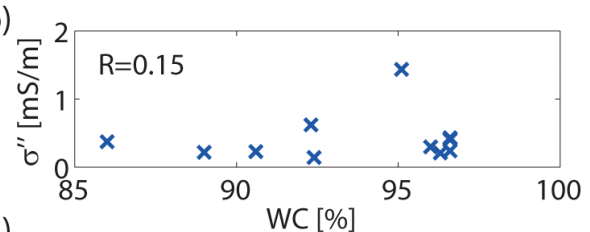

d)

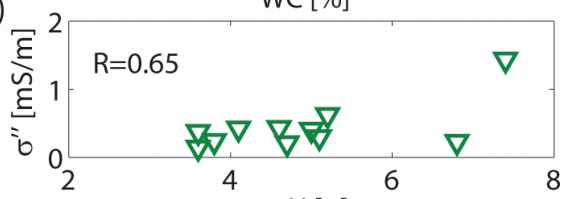

f)

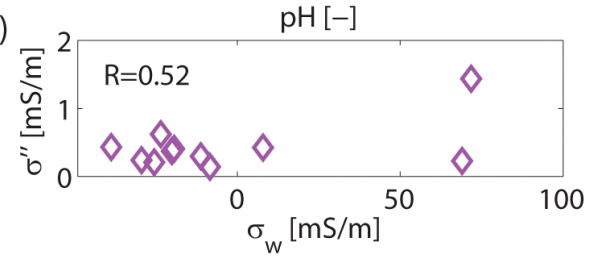

FIGURE 5

Correlations between the imaginary conductivity of peat and the physicochemical properties of the samples $\left(1 \mathrm{~Hz}, 20^{\circ} \mathrm{C}\right)$.

\section{IP investigation of peat}

a)
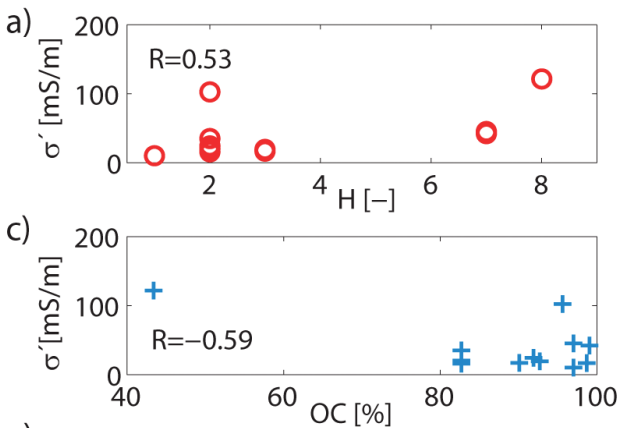

e)

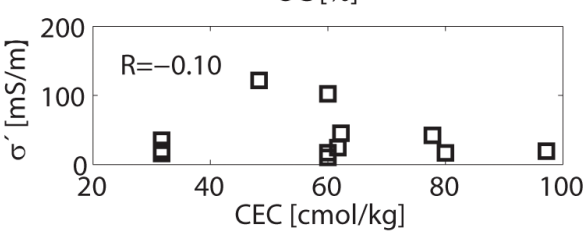

b)

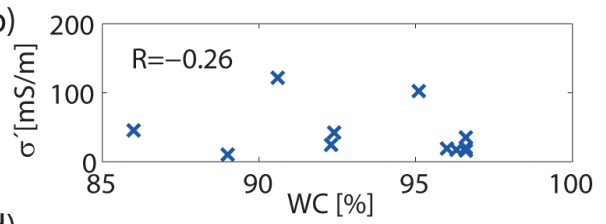

d)

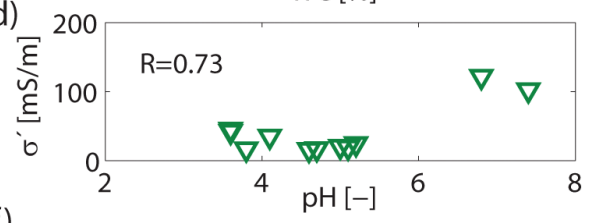

f)

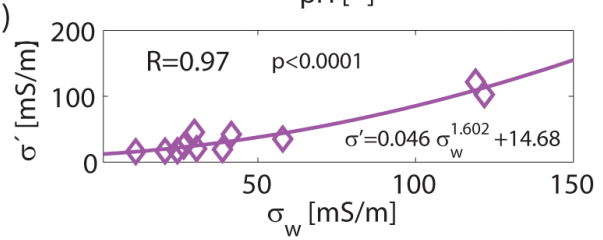

FIGURE 6

Relationships between the conductivity response of the peat samples (real part) and their physicochemical properties $\left(1 \mathrm{~Hz}, 20^{\circ} \mathrm{C}\right)$. The relationship between $\sigma^{\prime}$ and $\sigma_{w}$ is non-linear and has a p-value $<0.0001$ (Fig. 6f). 
a)
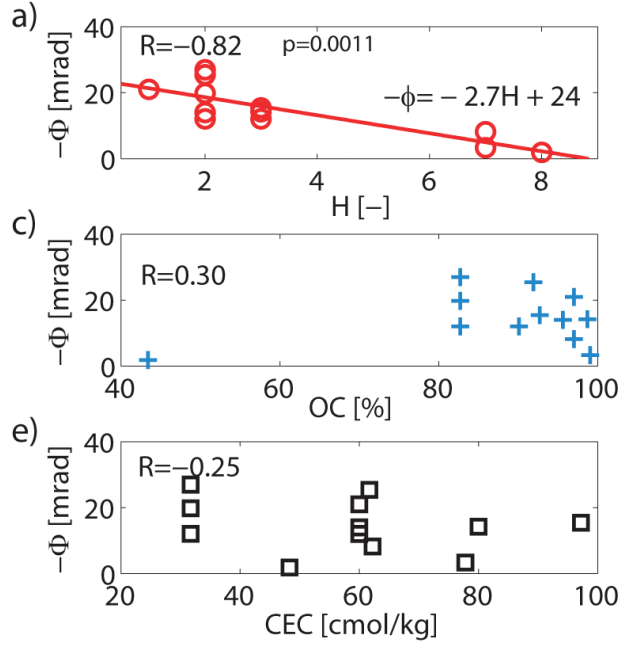

b)

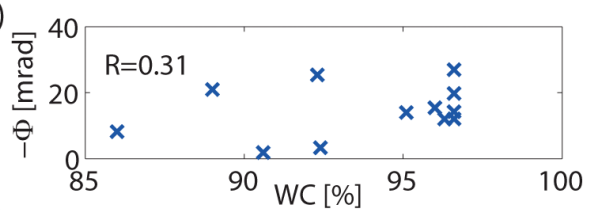

d)

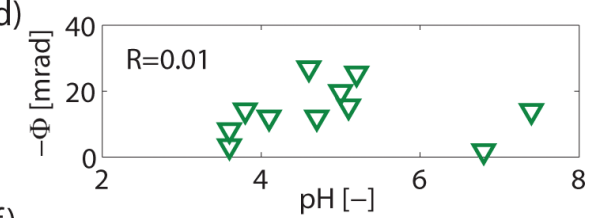

f)

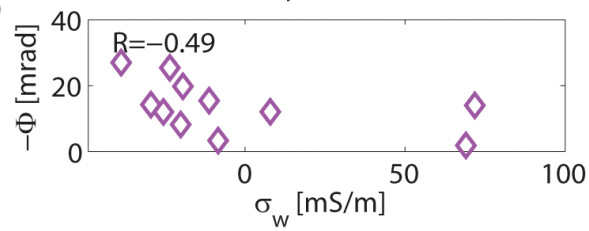

FIGURE 7

Phase angle relationships with the peat sample properties. The degree of humification shows an inverse correlation with the phase angle $(R=-0.82)$ for a p-value of $p=0.0011$ (Fig. 7a). considered in this study, the degree of humification is the one that affects the phase angle response the most.

\section{DISCUSSION}

The frequency analysis of the peat spectra showed that the ColeCole model is an appropriate phenomenological model to reproduce the low-frequency dispersion of peat samples of different composition. However, the results did not show a clear correlation between the peat sample properties investigated and the frequency parameter $\tau$. In our analysis, we only included physical and chemical properties that are not directly related to the microgeometry of the samples. The degree of humification is determined based on the soil texture at the macroscale, whereas the water content depends not only on the porosity of the material but also on the organic content and on the density of both the mineral and organic fraction. As showed by Ghorbani et al. (2009) for clay-rocks, the low-frequency polarization is not controlled by macropores, as textural changes are due to loss of water in micropores; in agreement with their results we did not find a correlation between the low-frequency $\tau$ and the water content. These results suggest that the frequency analysis cannot be used to determine univocally one of the six physical and chemical properties studied, due to the complexity of the low-frequency physical and chemical polarization mechanisms that are intrinsically coupled.

The single frequency analysis $(1 \mathrm{~Hz})$ of induced polarization (IP) measurements showed that the electrical response can be effectively used to obtain information on the peat sample properties. A correlation was found between the degree of humification and the phase angle, which is the field parameter to quantify the polarization response and is proportional to the ratio of physical properties quantifying the polarization $\left(\sigma^{\prime}\right)$ and the conductivity $(\sigma)$. Although a disturbance on the peat samples may have occurred, we may assume that the alteration of the matrix properties was minor compared to the structural differences among the samples. The structural differences in the sample studied range from a very fibrous low-humified peat to an amorphous highly decomposed peat. The degree of humification correlation with $\varphi$ suggests that a physical change in the structure of peat has a larger influence on the phase response than both the pore-fluid conductivity and the number of free exchange sites of the samples. During the injection of current in a peat sample, charged particles pass through interconnected pores and capillaries and build up around charged surface particles, forming a fixed layer (Stern layer) of charges at the solid/pore fluid interface. This phenomenon induces a polarization of the sample due to storage of charges, contributing to a phase delay measured between the injected current and the potential difference. Assuming that there is no exchange of ions between the fixed and the diffuse layer (Leroy et al. 2008), the polarization of the Stern layer is due to the movement of ions tangentially to the solid/pore fluid interface. For solid particles of spherical shape, the characteristic length associated to the polarization of the counter-ion atmosphere around the particles is the grain size (Schwarz 1962). In peat, the size of the solid particles changes according to the degree of humification, from long shape fibres (low-humified peat) to smaller and more spherical organic particles (high-humified peat). Therefore, as the electrochemical polarization of porous media is determined from the grain size distribution (Leroy et al. 2008), polarization of the Stern layer in peat should be affected by the length of the peat fibres and thus by the degree of humification. From our results, the polarization effect is higher for low degrees of humification, when the plant structure is more intact and charges can be built up around cell membranes. For higher degrees of humification, openings in the cell membranes of leaves and stems become larger as membranes decompose and eventually disappear, leaving an open framework structure (Landva and Pheeney 1980), reducing the polarizability. The lack of correlation between decomposition and $C E C$ can be explained by the different botanical composition of the tested peat, as $C E C$ depends on species distribution (Rippy and Nelson 2007). A significant correlation between $C E C$ and low-frequency polarization of peat was not found, in agreement with results of a previous study on clayrocks (Cosenza et al. 2008; Ghorbani et al. 2009). 
As shown in Fig. 6, the real conductivity response measured on the 12 peat samples of different composition is controlled mainly by the conductivity of the pore-fluid saturating the peat. The nonlinearity of the relationship between the bulk and pore fluid conductivity $\left(\sigma^{\prime} \propto \sigma_{w}^{1 .}{ }^{l .}\right)$ is explained by the pore-dilation effect (Comas and Slater 2004), while Archie's law is inappropriate to model the electrical conductivity of organic soils. The experimental data of the peat samples tested also fit equation (6), which is valid for saturated conditions. This confirms that the chemistry of the solution, through the concentration of dissolved ions in the electrolyte, plays the most relevant role on $\sigma^{\prime}$, rather than the index properties (organic content or humification) of the sample. Therefore, IP measurements on peat can be used to obtain information on the pore fluid conductivity and the level of decomposition of the organic matter from the measured $\sigma$ ' and $\phi$, respectively; moreover, the Cole-Cole model is effective in simulating the low-frequency electrical behaviour of peat and the derived normalized chargeability can be used to estimate the polarizability of the sample.

\section{CONCLUSIONS}

This paper has presented two different approaches to analyse IP measurements on peat. The frequency analysis of peat spectra fitting the experimental data with a Cole-Cole model showed no clear correlation between the mean relaxation time and the physicochemical properties of the peat samples. A linear relation between the calculated $m_{n}$ and the measured $\sigma^{\prime \prime}$ at a single frequency $(1 \mathrm{~Hz})$ was found. This suggests that the physicochemical properties of the samples affecting the conductivity and polarizability of the material can be directly determined by studying the low-frequency electrical response correlations with the sample properties at a single frequency.

A correlation was found between the degree of humification and the phase angle of the low-frequency induced polarization response of peat. The phase response is a function of humification due to a loss of structure during the decomposition of the organic matter. Therefore, an indication of the level of decomposition of the peat can be obtained from low-frequency electrical measurements, independently of the peat plant types. However, the polarization of organic soils is a complex phenomenon that involves multiple physical (e.g., geometry of the pore space), chemical (pore fluid chemistry) and biological (e.g., plant composition and degradation) properties; among these properties, the degree of humification of the peat plays a relevant role. The conductivity response of peat is non-linearly correlated with the pore fluid conductivity, which clearly appears as the main parameter confirming previous results on organic soils. These results provide a better understanding of the origin of the low-frequency polarization and electric conductivity of organic soils.

\section{ACKNOWLEDGEMENTS}

This work is part of the Delft Earth Research Center and the Geo-engineering Knowledge Center of TU Delft and Deltares. The authors wish to thank Markku Mäkilä and Ale Grundström of the Geological Survey of Finland for providing Finnish peat samples and peat data and Sanna Heinonen for assistance during CEC measurements.

\section{REFERENCES}

Airo M.L. 2005. Aerogeophysics in Finland 1972-2004: Methods, system characteristics and applications. Geological Survey of Finland, Special Paper 39, 1-197.

Archie G.E. 1942. The electrical resistivity log as an aid in determining some reservoir characteristics. Petroleum Transactions of AIME 146, 54-61.

Asadi A., Moayedi H., Huat B.B.K., Boroujeni F.Z., Parsaie A. and Sojoudi S. 2011. Prediction of zeta potential for tropical peat in the presence of different cations using artificial neural networks. International Journal of Electrochemical Science 6, 1146-1158.

Chelidze T.L. and Gueguen Y. 1999. Electrical spectroscopy of porous rocks: A review - I. Theoretical models. Geophysical Journal International 137, 1-15.

Cole K.S. and Cole R.H. 1941. Dispersion and absorption in dielectrics, Vol. I: Alternating current field. Journal of Chemical Physics 9, 341-351.

Comas X. and Slater L. 2004. Low-frequency electrical properties of peat. Water Resources Research 40, 1-9.

Comas X, Slater L. and Reeve A. 2004. Geophysical evidence for peat basin morphology and stratigraphic controls on vegetation observed in a northern peatland. Journal of Hydrology 295, 173-184.

Cosenza P., Ghorbani A., Florsch N. and Revil A. 2007. Effects of drying on the low-frequency electrical properties of Tournemire argillites. Pure and Applied Geophysics 164, 2043-2066. doi:10:1007/s0002400702530

Cosenza P., Ghorbani A., Revil A., Zamora M., Schmutz M., Jougnot D. and Florsch N. 2008. A physical model of the low-frequency electrical polarization of clay rocks. Journal of Geophysical Research 113, B08204. doi:10.1029/2007JB005539

Den Haan E.J. and Kruse G.A.M. 2007. Characterisation and engineering properties of Dutch peats. In: Characterisation and Engineering Properties of Natural Soils (eds T.S. Tan, K.K. Phoon, D.W, Hight and S. Leroueil), pp. 2101-2133. Taylor \& Francis.

El-Qady G., Metwaly M., El-Galladi A. and Ushijima K. 2005. Evaluation of peat formation using geoelectrical methods at Nile delta, Egypt. Memoirs of the Faculty of Engineering, Kyushu University 65, 1-13.

Ghorbani A., Cosenza P., Revil A., Zamora F., Schmutz M., Florsch N. and Jougnot D. 2009. Non-invasive monitoring of water content and textural changes in clay-rocks using spectral induced polarization: A laboratory investigation. Applied Clay Science 43, 493-502.

Gogo S. and Pearce D.M.E. 2009. Carbon, cations and CEC: Interactions and effects on microbial activity in peat. Geoderma 153, 76-86.

Hobbs N.B. 1986. Mire morphology and the properties and behaviour of some British and foreign peats. Quarterly Journal of Engineering Geology 19, 7-80.

Hunter R.J. 1981. Zeta Potential in Colloid Science: Principles and Applications. Academic Press.

Jougnot D., Ghorbani A., Revil A., Leroy P. and Cosenza P. 2010. Spectral induced polarization of partially saturated clay-rocks: A mechanistic approach. Geophysical Journal International 180, 210-224.

Keller G.V. and Frischknecht F.C. 1966. Electrical Methods in Geophysical Prospecting. Pergamon Press.

Kettridge N., Comas X., Baird A., Slater L., Strack M., Thompson D., Jol H. and Binley A. 2008. Ecohydrologically important subsurface structures in peatlands revealed by ground-penetrating radar and complex conductivity surveys. Journal of Geophysical Research 113, G04030. doi:10.1029/2008JG000787

Koch K., Kemna A., Irving J. and Holliger K. 2010. Impact of controlled changes in grain size and pore space characteristics on the hydraulic conductivity and spectral induced polarization responses of 'proxies' of saturated alluvial sediments. Hydrology and Earth System Sciences Discussions 7, 6057-6080. doi:10.5194/hessd-7-6057-2010 
Kruschwitz S., Binley A., Lesmes D. and Elshenawy A. 2010. Textural controls on low-frequency electrical spectra of porous media. Geophysics 75, WA113-WA123.

La Rochelle P., Sarrailh J., Tavenas F., Roy M. and Leroueil S. 1981. Causes of sampling disturbance and design of a new sampler for sensitive soils. Canadian Geotechnical Journal 18, 52-66.

Landva A.O. and Pheeney P.E. 1980. Peat fabric and structure. Canadian Geotechnical Journal 17, 416-435.

Leroy P. and Revil A. 2009. A mechanistic model for the spectral induced polarization of clay material. Journal of Geophysical Research 114, B10202. doi:10.1029/2008JB006114

Leroy P.A., Revil A., Kemna A., Cosenza P. and Ghorbani A. 2008. Complex conductivity of water-saturated packs of glass beads. Journal of Colloid and Interface Science 321, 103-117.

Lesmes D.P. and Frye K.M. 2001. Influence of pore fluid chemistry on the complex conductivity and induced-polarization responses of Berea sandstone. Journal of Geophysical Research 106, 4079-4090.

Lesmes D.P. and Morgan F.D. 2001. Dielectric spectroscopy of sedimentary rocks. Journal of Geophysical Research 106, 13,329-13,346. doi:10.1029/2000JB900402

de Lima O.A.L. and Sharma M.M. 1992. A generalized Maxwell-Wagner theory for membrane polarization in shaly sands. Geophysics $\mathbf{5 7}$, 431-440.

Mäkilä M. 2004. Electric conductivity within a raised bog in southeastern Finland: Implications for bog development. In: $7^{\text {th }}$ INTECOL International Wetlands Conference, Utrecht, The Netherlands, 25-30 July 2004. Utrecht University.

Mansoor N. and Slater L. 2007. On the relationship between iron concentration and induced polarization in marsh soils. Geophysics 72, A1-A5.

Marshall D.J. and Madden T.R. 1959. Induced polarization: A study of its causes. Geophysics 24, 790-816.

Moore P.D. and Bellamy D.J. 1974. Peatlands. Elek Science.

Pelton W.G., Ward S.H., Hallof P.G., Sill W.R. and Nelson P.H. 1978. Mineral discrimination and removal of inductive coupling with multifrequency IP. Geophysics 43, 588-609.

Ponziani M., Ngan-Tillard D.J.M. and Slob E.C. 2011. A new prototype cell to study electrical and geo-mechanical properties of peaty soils. Engineering Geology 119, 74-81.

von Post L. 1922. Sveriges Geologiska Undersöknings torvinventering och några av dess hittils vunna resultat (SGU peat inventory and some preliminary results). Svenska Mosskulturföreningens Tidskrift 36, 1-37 (in Swedish).

Puranen R., Mäkilä M. and Säävuori H. 1999. Electric conductivity and temperature variations within a raised bog in Finland: Implications for bog development. The Holocene 9, 13-24.

Puranen R., Mäkilä M., Sulkanen K. and Grundström A. 1997. A new apparatus for electric conductivity and temperature logging of soft sediments. In: Geological Survey of Finland, Current Research 1995-96 (ed. S. Autio), pp. 149-155. Geological Survey of Finland.

Puustjarvi V. and Robertson R.A. 1975. Physical and chemical properties. In: Peat in Horticulture (eds D.W. Robinson and J.G.D. Lamb), pp. 23-38. Academic Press.

Rippy J.F.M. and Nelson P.V. 2007. Cation exchange capacity and base saturation variation among Alberta, Canada, moss peats. HortScience 42, 349-352.

Ruuhijärvi R. and Hosiaisluoma V. 1989. Atlas of Finland. In: Biogeography, Nature Conservation, $5^{\text {th }}$ edn (ed. P. Alalammi), pp. 141-143. National Board of Survey and Geographical Society of Finland.
Rydin H. and Jeglum J. 2006. Peatlands habitats. In: The Biology of Peatlands (Biology of Habitats) (eds H. Rydin and J.K. Jeglum), pp. 1-19. Oxford University Press.

Säävuori H. and Mäkilä M. 2004. Airborne geophysical mapping of peat deposits in the Teuravuoma mire complex. In: Wise Use of Peatlands: Proceedings of the $12^{\text {th }}$ International Peat Congress, Tampere, Finland, 6-11 June 2004. International Peat Society.

Schwarz G. 1962. A theory of the low-frequency dielectric dispersion of colloidal particles in electrolyte solution. Journal of Physical Chemistry 66, 2636-2642.

Scott J.B.T. and Barker R.D. 2003. Determining pore-throat size in Permo-Triassic sandstones from low-frequency electrical spectroscopy. GeophysicalResearchLetters 30, 1450. doi:10.1029/2003GL016951

Seladji S., Cosenza P., Tabbagh A., Ranger J. and Richard G. 2010. The effect of compaction on soil electrical resistivity: A laboratory investigation. European Journal of Soil Science 61, 1043-1055.

Sepulveda-Cuevas L.A., Contreras-Villacura E.G. and Palma-Toloza C.L. 2008. Magellan Peat (Spaghnum magallanicum) as natural adsorbent of recalcitrant synthetic dyes. Journal of Soil Science and Plant Nutrition 8, 31-43.

Siegel D.I. 1988. The recharge-discharge function of wetlands near Juneau, Alaska: Part I. Hydrogeological investigations. Ground Water 26, 427-434.

Skempton A.W. and Petley D.J. 1970. Ignition loss and other properties of peats and clays from Avonmouth, King's Lynn and Cranberry Moss. Géotechnique 20, 343-356.

Slater L., Comas X., Ntarlagiannis D, and Roy Moulik M. 2007. Resistivity-based monitoring of biogenic gases in peat soils. Water Resources Research 43, W10430. doi:10.1029/2007WR006090

Slater L. and Reeve A. 2002. Investigating peatland stratigraphy and hydrogeology using integrated electrical geophysics. Geophysics $\mathbf{6 7}$, 365-378.

Stogryn A. 1971. Equations for calculation the dielectric constant of saline water. IEEE Transactions on Microwave Theory and Techniques 19, 733-736.

Szalay A. 1964. Cation exchange properties of humic acids and their importance in the geochemical enrichment of $\mathrm{UO}_{2}^{++}$and other cations. Geochimica et Cosmochimica Acta 28, 1605-1614.

Theimer B.D., Nobes D.C. and Warner B.G. 1994. A study of the geoelectrical properties of peatlands and their influence on ground-penetrating radar surveying. Geophysical Prospecting 42, 179-209.

Thorpe V.A. 1973. Collaborative study of the cation exchange capacity of peat materials. Journal of the Association of the Official Analytical Chemists (AOAC) 56, 154-157.

Titov K., Komarov V., Tarasov V and Levitski A. 2002. Theoretical and experimental study of time domain-induced polarization in water-saturated sands. Journal of Applied Geophysics 50, 417-433.

Vanhala H. and Soininen H. 1995. Laboratory technique for measurement of spectral induced polarization response of soil samples. Geophysical Prospecting 43, 655-676.

Ward S.H. 1990. Geotechnical and Environmental Geophysics, Volume I: Review and Tutorial. SEG.

Weller A., Nordsiek S. and Bauerochse A. 2006. Spectral induced polarization - A geophysical method for archaeological prospection in peatlands. Journal of Wetland Archaeology 6, 105-125. 


\section{EAGE}

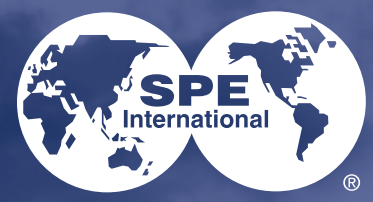

\section{EUROPEC}

\section{( London ${ }^{2} 13$ \\ Call for papers deadline 15 January 2013}

\section{Changing Frontiers \\ (1) ExponMobil www.eoge.org 1:}

